\title{
Thrombolysis in high-risk patients with left-sided obstructive prosthetic valve thrombosis
}

\author{
Refai Showkathali1,2, Radhapriya Yalamanchi' ${ }^{1}$, Abraham Oomman¹, K Abhinaya ${ }^{1}$ \\ 1 Department of Cardiology, Apollo Main Hospital, Chennai, India \\ 2 Apollo Hospital Educational and Research Foundation, Chennai, India
}

Correspondence to: Refai Showkathali, MBBS, MRCP(UK), FRCP(Lon), FESC, FACC, Apollo Hospital Educational and Research Foundation, Greams Road, Chennai 600 006, India phone: +914428296150, email: refais@gmail.com Received: July 242020. Revision accepted: September 9, 2020. Published online: September 21, 2020. Kardiol Pol. 2020; 78 (11): 1166-1168 doi:10.33963/KP.15604

Copyright by the Author(s), 2020
Introduction Prosthetic valve thrombosis (PVT) is one of the most dreaded complications of mechanical heart valves. The incidence of PVT is estimated at $0.3 \%$ to $1.3 \%$ per patient year in developed countries and as high as $6.1 \%$ within 6 months of valve replacement in developing countries. ${ }^{1,2}$ In a recent study of a new generation bioprosthetic surgical aortic valve, thromboembolic event rate was $2.3 \%$ within 30 days. $^{3}$ Published guidelines differ over the best line of therapy for PVT; the European Society of Cardiology valve guidelines recommend surgery as a class I treatment for obstructive PVT (OPVT) in critically ill patients without a serious comorbidity and to consider standard-dose thrombolytic therapy (TT) when surgery is not available or deemed high risk (class IIa recommendation), while the 2017 American College of Cardiology/American Heart Association focussed update recommends urgent initial treatment with either slow-infusion low-dose TT, or emergency surgery (class I recommendation) for OPVT. ${ }^{4,5}$ We aimed to evaluate the clinical profile, management strategies, and outcome of patients presenting with left sided mechanical OPVT.

Methods We included patients admitted with mechanical OPVT to our institute between July 2014 and July 2019. Our centre is a tertiary referral institute capable of emergency valve surgery. Prosthetic valve thrombosis was confirmed based on clinical presentation, transthoracic echocardiography (TTE), and fluoroscopy findings. Patients with infective endocarditis and nonobstructive PVT were excluded from the study. We defined a subtherapeutic International Normalized Ratio (INR) as 2 or less in patients with an aortic mechanical valve and 2.5 or less in patients with a mitral mechanical valve.

The dose and choice of TT (streptokinase/tenecteplase / alteplase) were at the discretion of the treating cardiologist. Thrombolytic therapy was considered to be successful if there was a $50 \%$ reduction in the transvalvular gradient on TTE with clinical improvement in the absence of death or need for surgery.

Statistical analysis Categorical variables are expressed as numbers and percentages and continuous variables are expressed as means (SD), unless otherwise stated. Comparison of categorical variables was done by the Fisher exact test and comparison of continuous variables was done either by the $t$ test (both paired and unpaired) or the Mann-Whitney test based on the normality of data. Data analysis was carried out by SPSS, version 25.0 (IBM, New York, New York, United States). A $P$ value of less than 0.05 was considered significant. The study was conducted in compliance with the ethical standards of the responsible institution as well as with the 1975 Declaration of Helsinki.

Results and discussion A total of 46 patients (mean [SD] age, 50 [12] years; female sex, 19) were included in the study. Aortic OPVT was predominant in 27 patients (59\%), mitral OPVT in 18 (39\%), while 1 patient had both valves involved (2\%). Valve design was mostly bileaflet (65.2\%), with tilting disc in $30.4 \%$ and ball and cage model in $4.4 \%$ of patients. The median (IQR) duration between surgery and this OPVT admission was significantly shorter in the mitral compared to aortic OPVT (49 [20-83] months vs 78 [38-145] months; $P=0.04)$. The mean (SD) 


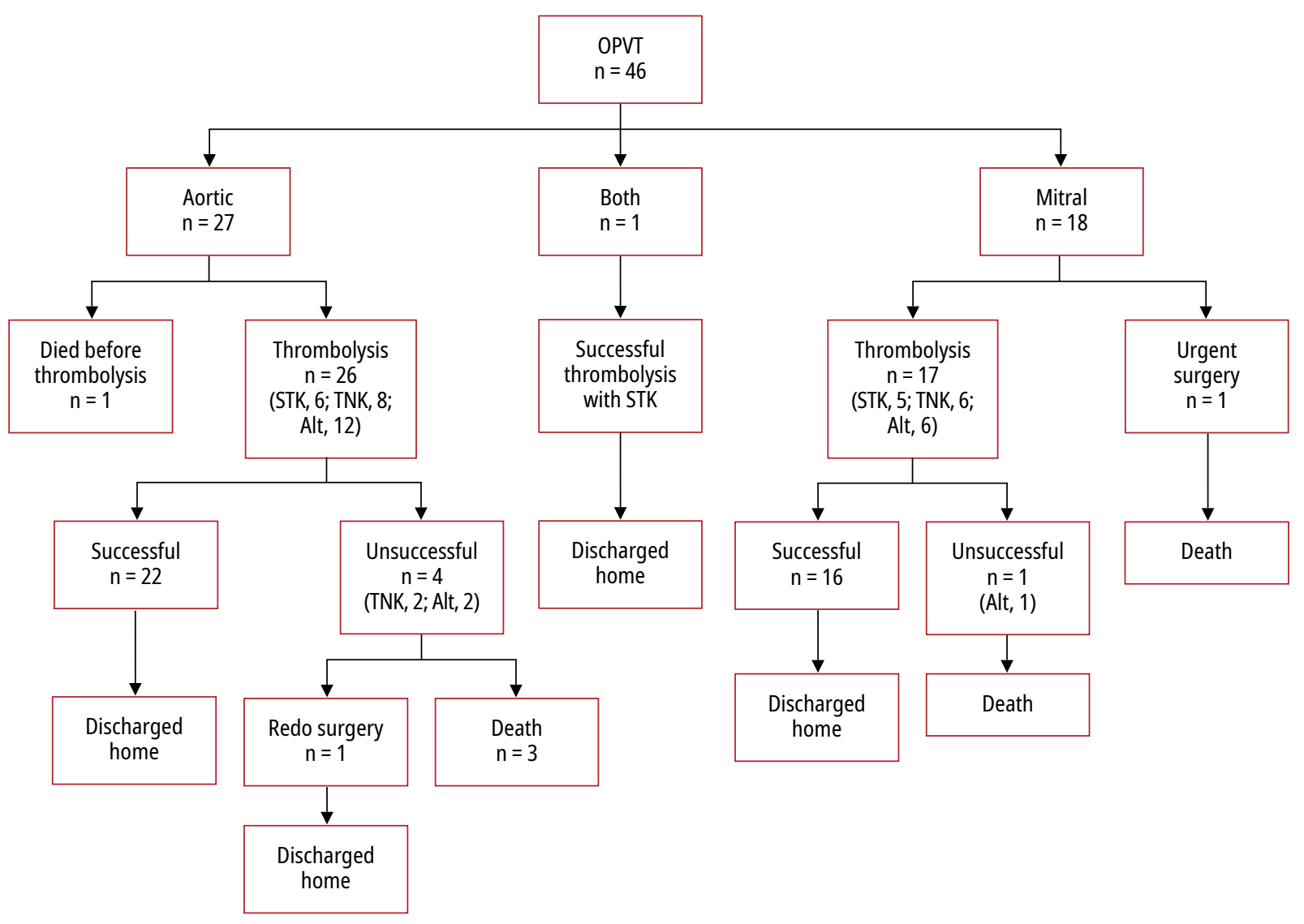

FIGURE 1 Management flow chart of patients admitted with obstructive prosthetic valve thrombosis Abbreviations: Alt, alteplase; OPVT, obstructive prosthetic valve thrombosis; STK, streptokinase; TNK, tenecteplase

pressure gradient (MPG) was 71 (26) $\mathrm{mm} \mathrm{Hg}$ and 25 (7) $\mathrm{mm} \mathrm{Hg}$ in aortic and mitral OPVT, respectively. The mean (SD) admission INR was 2.02 (0.6), and 35 patients (76\%) had subtherapeutic INR values (Supplementary material, Table S1).

Out of the 44 patients who had TT (streptokinase, 27\%; tenecteplase, 32\%; and alteplase, $41 \%$ ), the therapy failed in 5 individuals (4 aortic / 1 mitral; FIGURE 1). In those who had successful TT (89\%), the postlysis echocardiography showed a mean (SD) pressure gradient of 31.3 (24.5) $\mathrm{mm} \mathrm{Hg}$ in aortic (prelysis, 71 [26] $\mathrm{mm} \mathrm{Hg} P$ < 0.0001 ) and 9 (4) $\mathrm{mm} \mathrm{Hg}$ (prelysis, 25 [6.1] mm Hg; $P<0.0001$ ) in mitral OPVT (Supplementary material, Figure 1 ).

Six of the 46 patients (13\%) died during hospital stay, including the patient who underwent surgery without TT. Three patients (7\%) had intracranial hemorrhage and 2 patients (4\%) had ischemic stroke. One patient (2\%) had gastric bleed requiring blood transfusion. The in-hospital mortality (IHM) rate of patients who had TT in our study was $9.1 \%$ (4 out of 44 ). During a median (IQR) follow-up period of 21 (10-44) months, 3 patients (7.5\%) died and 2 (5\%) underwent a redo valve surgery due to recurrent OPVT. The overall mortality rate of all patients with OPVT included in the study was $19.6 \%$, while in thrombolysed patients it was $15.9 \%$.
Our study has a few unique findings when compared with some of the previous observational reports. Firstly, our study included more cases of aortic OPVT compared to mitral OPVT. This could partly be explained by the fact that our study included only obstructive PVT; patients with mitral OPVT might not have survived to reach the hospital, whereas patients with aortic OPVT tolerated it better. Most previous studies included both obstructive and nonobstructive PVT; like the PRO-TEE (Prosthetic Valve Thrombolysis-Role of Transesophageal Echocardiography) registry, TROIA (Comparison of Different TEE-Guided Thrombolytic Regimens for Prosthetic Valve Thrombosis), and PROMETEE (Ultraslow Thrombolytic Therapy: a Novel Strategy in the Management of Prosthetic Mechanical Valve Thrombosis and the Predictors of Outcome) studies had $15 \%, 50 \%$, and $36 \%$ of nonobstructive PVT respectively. ${ }^{6-8}$ This could be the reason for the higher prevalence of mitral PVT included in those studies. There was one study involving only patients with nonobstructive PVT and $97 \%$ had mitral involvement. ${ }^{9}$

There were 2 important meta-analyses and 1 systematic review related to the management of PVT comparing TT versus surgery, from which the European and American guidelines were derived. Two of these meta-analyses did not 
differentiate patients with obstructive and nonobstructive PVT in their analysis. ${ }^{10-11}$ The systematic review by Huang et $\mathrm{al}^{12}$ on patients with OPVT included 17 studies comprising 756 patients who received TT and 13 studies comprising 662 patients who received surgery for OPVT. This showed a 30 -day mortality rate of $8 \%$ in those receiving TT as compared with $15 \%$ in those who underwent surgery, and the recurrence rate was higher (13\%) in the thrombolysis group. Based on that, the authors recommended thrombolysis as the first choice for patients in NYHA Class I / II with severe comorbidities associated with a high surgical operative mortality and recommended surgery as the preferred therapy for patients in NYHA class III / IV and with a large thrombus $\left(\geq 0.8 \mathrm{~cm}^{2}\right)$. In this analysis, only $65 \%$ of the thrombolysis patients were in NYHA class III / IV and their success rate was only $74 \%$ compared to $81 \%$ in NYHA class I / II patients. ${ }^{12}$

Naturally, due to the inclusion of only OPVT, our study included more patients (85\%) with NYHA class III / IV symptoms, and thrombolysis success rate in this group was $87 \%$. The other studies which included both nonobstructive and OPVT had comparatively lower number of patients with NYHA class III / IV symptoms, for example, TROIA and PROMETEE study had $41 \%$ and $36 \%$ of patients in NYHA class III / IV, respectively. Despite our study population being considered high risk, the mortality rate of patients who underwent thrombolysis (9.1\%) was similar to the previous available data of around $8 \%$ to $9 \%$.

Another strength of our study is longer follow-up period with a median (IQR) of 21 (10-44) months, while most previous studies had 30-day outcome data. The recurrence rate was low at $5 \%$ in our study, whereas in the systematic review, the recurrence rate of OPVT in patients who had thrombolysis was $13 \%$ with no clear time frame mentioned. ${ }^{12}$

Our study is a single-center observational analysis, with its inherent limitation of a retrospective study. Only the dose of streptokinase was followed uniformly (250 000 IU bolus followed by $100000 \mathrm{IU} / \mathrm{h}$ infusion) while the dose of tenecteplase and alteplase used differed between the treating cardiologists. Transesophageal echocardiogram was not performed routinely for all patients with OPVT in our unit, and therefore, data are unavailable.

In conclusion, our study shows that even in high-risk patients with mechanical OPVT, thrombolysis is beneficial with $89 \%$ success rate and $5 \%$ recurrence rate during a longer follow-up period. In OPVT, a randomized prospective multicenter study is needed to provide evidence of superiority and safety of thrombolysis over surgery, and to identify those patients who benefit most from thrombolysis.

\section{SUPPLEMENTARY MATERIAL}

Supplementary material is available at www.mp.pl/kardiologiapolska.

\section{ARTICLE INFORMATION}

CONFLICT OF INTEREST None declared.

OPEN ACCESS This is an Open Access article distributed under the terms of the Creative Commons Attribution-NonCommercial-NoDerivatives $4.0 \mathrm{In}$ ternational License (CC BY-NC-ND 4.0), allowing third parties to download articles and share them with others, provided the original work is properly cited, not changed in any way, distributed under the same license, and used for noncommercial purposes only. For commercial use, please contact the journal office at kardiologiapolska@ptkardio.pl.

HOW TO CITE Showkathali R, Yalamanchi R, 0omman A, et al. Thrombolysis in high-risk patients with left-sided obstructive prosthetic valve thrombosis. Kardiol Pol. 2020; 78: 1166-1168. doi:10.33963/KP.15604

\section{REFERENCES}

1 Roudaut R, Serri K, Lafitte S. Thrombosis of prosthetic heart valves: diagnosis and therapeutic considerations. Heart. 2007; 93: 137-142.

2 Talwar S, Kapoor CK, Velayoudam D, et al. Anticoagulation protocol and early prosthetic valve thrombosis. Indian Heart J. 2004; 56: 225-228.

3 Bartuś K, Litwinowicz R, Kuśmierczyk M, et al. Primary safety and effectiveness feasibility study after surgical aortic valve replacement with a new generation bioprosthesis: one-year outcomes. Kardiol Pol. 2018; 76: 618-624.

4 Baumgartner H, Falk V, Bax JJ, et al. 2017 ESC/EACTS guidelines for the management of valvular heart disease. Eur Heart J. 2017; 38: 2739-2791.

5 Nishimura RA, Otto CM, Bonow RO, et al. 2017 AHA/ACC focused update of the 2014 AHA/ACC guideline for the management of patients with valvular heart disease. J Am Coll Cardiol. 2017; 70: 252-289.

6 Tong AT, Roudaut R, Ozkan M, et al. Prosthetic Valve Thrombolysis-Role of Transesophageal Echocardiography (PRO-TEE) Registry Investigators; transesophageal echocardiography improves risk assessment of thrombolysis of prosthetic valve thrombosis: results of the international PRO-TEE registry. J Am Coll Cardiol. 2004; 43: 77-84.

7 Ozkan M, Gunduz S, Biteker M, et al. Comparison of different TEE-guided thrombolytic regimens for prosthetic valve thrombosis: the TROIA trial. JACC Cardiovasc Imaging. 2013; 6: 206-216.

8 Özkan M, Gündüz S, Gürsoy OM, et al. Ultraslow thrombolytic therapy: a novel strategy in the management of PROsthetic MEchanical valve Thrombosis and the prEdictors of outcomE: the ultra-slow PROMETEE trial. Am Heart J. 2015; 170: 409-418.e1.

9 Mutuberría-Urdaniz M, Rodríguez-Palomares JF, Ferreira I, et al. Non-obstructive prosthetic heart valve thrombosis (NOPVT): really a benign entity? Int J Cardiol. 2015; 197: 16-22.

10 Karthikeyan G, Senguttuvan NB, Joseph J, et al. Urgent surgery compared with fibrinolytic therapy for the treatment of left-sided prosthetic heart valve thrombosis: a systematic review and meta-analysis of observational studies. Eur Heart J. 2013; 34: 1557-1566.

11 Castilho FM, Sousa MR, Mendonca ALP, et al. Thrombolytic therapy or surgery for valve prosthesis thrombosis: systematic review and meta-analysis. J Thromb Haemost. 2014; 12: 1218-1228.

12 Huang G, Schaff HV, Sundt TM, et al. Treatment of obstructive thrombosed prosthetic heart valve. J Am Coll Cardiol. 2013; 62: 1731-1736. 